Please do not remove this page

RMIT

UNIVERSITY

\title{
Long wire antenna-like behavior of uninsulated overhead distribution cables
}

Fernando, Sahan; Rowe, Wayne; Wong, Khoi Loon

https://researchrepository.rmit.edu.au/esploro/outputs/9921858585101341/filesAndLinks?institution=61RMIT_INST\&index=null

Fernando, S., Rowe, W., \& Wong, K. L. (2012). Long wire antenna-like behavior of uninsulated overhead distribution cables. IEEE Transactions on Power Delivery, 27(3), 1116-1123.

https://doi.org/10.1109/TPWRD.2012.2196769

Document Version: Accepted Manuscript

Published Version: https://doi.org/10.1109/TPWRD.2012.2196769

Repository homepage: https://researchrepository.rmit.edu.au

(C) 2012 IEEE

Downloaded On 2023/04/27 00:19:43 +1000

Please do not remove this page 
Thank you for downloading this document from the RMIT Research Repository.

The RMIT Research Repository is an open access database showcasing the research outputs of RMIT University researchers.

RMIT Research Repository: http://researchbank.rmit.edu.au/

\section{Citation:}

Fernando, S, Rowe, W and Wong, K 2012, 'Long wire antenna-like behavior of uninsulated overhead distribution cables', IEEE Transactions on Power Delivery, vol. 27, no. 3, pp. 1116-1123.

See this record in the RMIT Research Repository at:

http://researchbank.rmit.edu.au/view/rmit:16399

Version: Accepted Manuscript

Copyright Statement: (C) 2012 IEEE

Link to Published Version:

http://dx.doi.org/10.1109/TPWRD.2012.2196769

\section{PLEASE DO NOT REMOVE THIS PAGE}




\title{
Long Wire Antenna-like behavior of Un- Insulated Overhead Distribution Cables
}

\author{
S. C. Fernando, Student Member, IEEE, W. S. T. Rowe, Member, IEEE, and K. L. Wong, Member, \\ IEEE
}

\begin{abstract}
Un-insulated overhead distribution cables are evaluated in terms of their propagation and radiation behavior when excited by a partial discharge pulse. Low attenuation levels at high frequency and a traveling wave radiation pattern are observed for a single Aluminum cable. The dominant radiated frequency components of surface discharge and dry-band arcing are experimentally evaluated, and a high level of activity is observed in the $400-600 \mathrm{MHz}$ and $900-1000 \mathrm{MHz}$ bands. High directivity values at specific angles are also recorded at 400 and $900 \mathrm{MHz}$ for both single and three cable distribution systems. These findings show that a partial discharge signal will travel for a significant distance along a cable and leak radiation predominantly in a specific direction, thus assisting the design of RF based discharge detection and localization system.
\end{abstract}

Index Terms - Partial Discharge, long wire antenna, traveling wave radiation, $\mathrm{RF}$ sensors, aluminum cable

\section{INTRODUCTION}

$\mathrm{P}$ artial discharge (PD) is a key contributor to failures in high voltage (HV) electrical insulation systems. These failures often lead to catastrophic events such as pole top fires and bush fires, and cause damage to power infrastructure worth of millions of dollars. The electrical industry has implemented preventative measures to avoid damage due to electrical discharges by using new epoxy insulator materials which can handle the stress from the partial discharge, and by quality controlling insulator manufacturing. However, existing infrastructure using outdated technology still presents a problem for the electrical industry. Hence a real time PD detection mechanism which can detect and locate discharges in their early stages is essential in the prevention of catastrophic failure.

Partial discharge is a random activity with a very narrow pulse width. It has been shown that the magnitude of a PD pulse can be related to the charge inside a cavity fault and the voltage across the insulator [1]. Previous research shows that this PD pulse consists of a broad band range of frequencies,

S. C. Fernando is with the School of Electrical and Computer Engineering, RMIT University, Melbourne, Australia (e-mail: sahan.fernando@rmit.edu.au).

W. S. T. Rowe is with the School of Electrical and Computer Engineering, RMIT University, Melbourne, Australia (e-mail: wayne.rowe@ rmit.edu.au).

K. L. Wong is with the School of Electrical and Computer Engineering, RMIT University, Melbourne, Australia (e-mail: alan.wong@ @rmit.edu.au). even up to the $\mathrm{GHz}$ region [2-4]. The UHF components generated by PD activity is currently used to detect and locate faults in HV transformers and Gas Insulated Substations [5-7]. While UHF couplers have widely been used in these scenarios, Radio Frequency (RF) sensors have rarely been used in the detection and location of faulty HV distribution insulators. The detection of PD in the VHF range has been proposed [8]. However RF detection systems at higher frequencies could be advantageous, as interference from common communication bands can be easily avoided.

The Rogowski Coil is a commonly used sensor for various detection techniques. It has been widely used in detecting faults from XLPE cables [9-12], and it has also been used in PD localization systems [9]. However it is impractical and hazardous to use a Rogowski Coil to detect PD pulse from bare Aluminum cables since direct attachment of the sensors is required. The Rogowski coil is also incapable of detecting very high frequency components such as in the $\mathrm{GHz}$ region. Therefore it is important to look at the possibility of using RF sensors for PD detection and localization in bare cable distribution systems.

A representation of the proposed PD detection system using RF sensing is shown in Fig. 1. A PD pulse from a faulty insulator propagates along a bare Aluminum cable, radiating energy in a specific pattern at each frequency. With an understanding of the propagation and radiation behavior of these cables, sensing antennas can be used to receive and monitor radiation at given angles for a particular frequency. If a PD signature is detected by more than one of these monitoring stations, a localization algorithm can determine the exact position of the faulty insulator.

Critical performance criteria for HV cable sensing systems are: PD pulse propagation, attenuation of particular frequency components, and radiation from the cable into the far field. XLPE cables are covered conductors that are widely used in the HV industry, and have been extensively evaluated in terms of PD pulse propagation. It has been shown that the XLPE cable displays significant attenuation at high frequencies due to its insulation layer $[13,14]$, and also that its core has less contribution towards the attenuation than the insulation layer [14]. This paper investigates PD propagation along an uninsulated Aluminum cable (AS 1531 Conductors) [15], which are primarily used in $11 \mathrm{kV}$ power distribution systems. The 
propagation is assessed in terms of the ability of the cable to be used as part of a detached RF detection and localization system for faulty HV insulators in distribution networks.

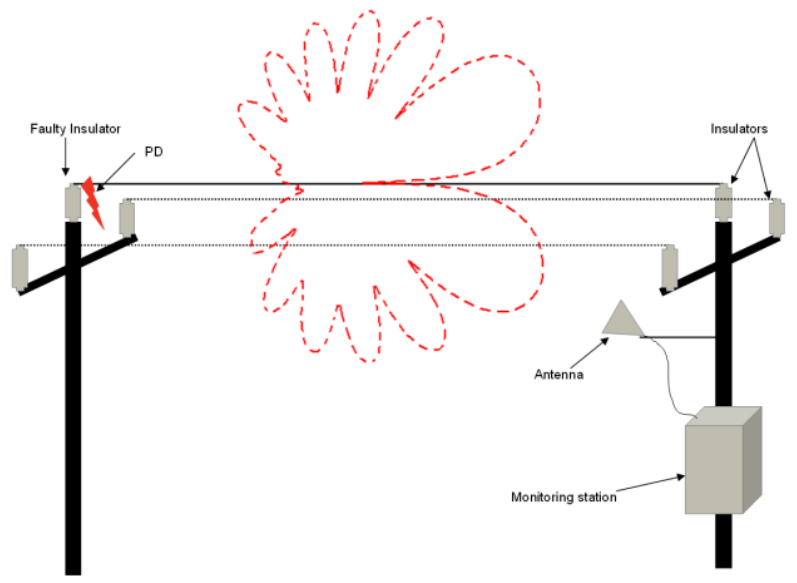

Fig. 1. The proposed RF sensing architecture

\section{CST MicROWAVE STUDIO AND THE FINITE INTEGRAL TECHNIQUE (FIT)}

The propagation and radiation from a single wire earth return (SWER) cable at $100 \mathrm{kHz}$ has previously been investigated using theoretical model created in MATLAB [16]. ATP and EMTP simulations employing a quasi-static approximation using Carson and Polaczeck theory has shown PD pulse propagation along an XLPE cable [12, 17, 18]. This theory assumes that the height of the cable is significantly small compared to the wavelength at the frequency used for simulation [19]. Fundamental antenna theory and Maxwell's equations can be used to reduce inaccuracies associated with high frequency simulations [19]. 3D simulations based on the Finite Element Method (FEM) and the Finite Integral Technique (FIT) (which apply Maxwell equations) can be used in these situations, since they enable the simulation of the real physical cable or system.

The Finite Integral Technique uses the integral form of Maxwell's equation rather than their discrete forms. This can be used for the numerical simulation of various electromagnetic problems ranging from static field calculations to high frequency scenarios in either time or frequency domain [20]. CST Microwave studio is a commercial software package that uses FIT in combination with the Perfect Boundary Approximation (PBA) to yield a high accuracy. Unlike FEM based software it is capable of simulating electrically large structures in the time domain, which is more computationally efficient than using the frequency domain [21]. However, significant computer resources are still required to accurately evaluate large (in terms of a wavelength) problems.

\section{ANALYSis OF PD PUlse Propagation IN UN-INSULATED ALUMINUM CABLES}

\section{A. Simulation Setup}

The typical PD can be approximated numerically by a Gaussian pulse [22]. A Gaussian pulse with centre frequency of $1.25 \mathrm{GHz}$, bandwidth $2.5 \mathrm{GHz}$ and a $1 \mathrm{~V}$ amplitude has been used as the excitation source. The cable structure simulated in CST is shown in Fig. 2. A $5 \mathrm{~m}$ long un-shielded Aluminum overhead distribution cable resides $10 \mathrm{~m}$ above a ground plane made of dry soil. To minimise the effect of reflection, perfectly matched layer (PML) boundaries were employed at the edges of the simulation cell. Voltage monitors are located at every meter along the length of the cable, including one at the source. A discrete port has been used to excite the cable, connected via a $50 \Omega$ resistor to minimize impedance mismatch.

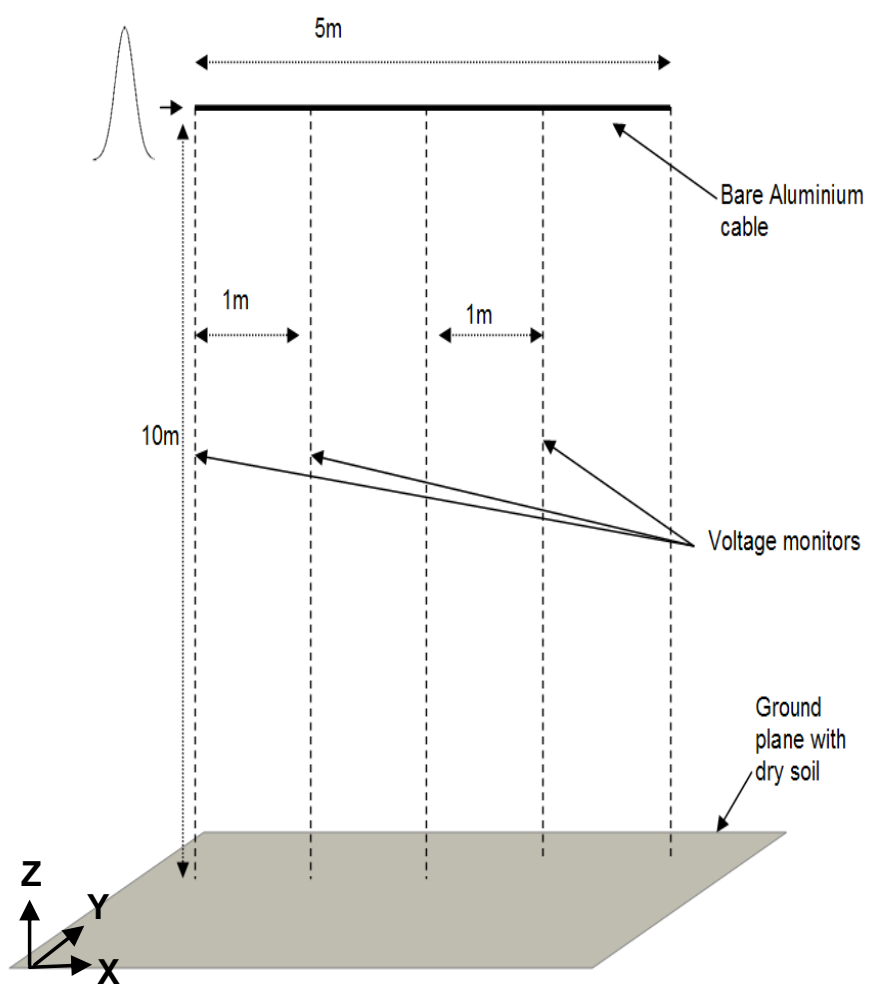

Fig. 2. Overhead distribution cable structure for the pulse propagation simulation

\section{B. Pulse propagation}

Fig. 3 shows the signal recorded at each of the voltage monitors along the length of the $5 \mathrm{~m}$ cable. The voltage monitor at $0 \mathrm{~m}$ shows the input pulse after transition though the discrete port. This is assumed to be the reference level at the input to the cable. As the pulse traverses along the cable, the amplitude drops slightly, and the tail of the pulse is distorted slightly by the frequency dependant characteristics of the cable.

A Discrete Fourier Transformation (DFT) was performed in MATLAB to analyze the Power Spectral Density (PSD) of the 
signal observed at each voltage monitor. This was used to calculate the attenuation verses frequency, the results of which are shown in Fig. 4. It has been shown that XLPE cables have considerable attenuation at high frequencies due to the surrounding dielectric layer [13, 14], a typical value being 2 $\mathrm{dB} / \mathrm{m}$ at $1 \mathrm{GHz}$. The simulation results for bare Aluminum cables show a significantly lower level of attenuation. At 2.5 $\mathrm{GHz}$, an attenuation of only $0.14 \mathrm{~dB} / \mathrm{m}$ is recorded.

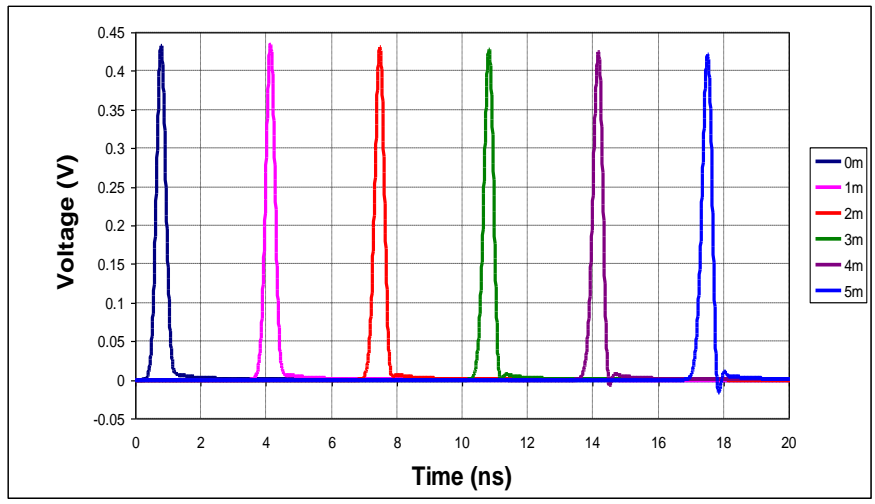

Fig. 3. Pulse propagation along an un-insulated cable from $0 \mathrm{~m}$ to $5 \mathrm{~m}$

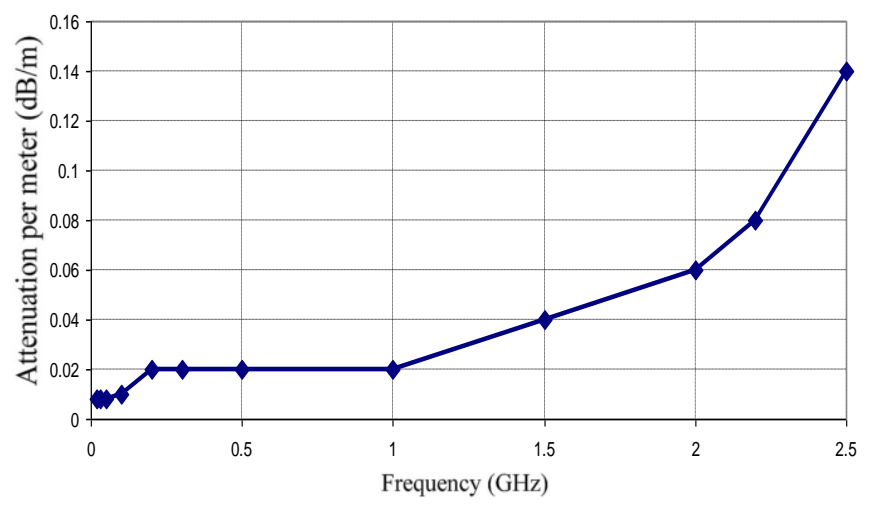

Fig. 4. Attenuation per meter vs frequency for un-insulated Aluminum cable

It can be deduced using antenna theory [23] that the radiation loss from the power line is very low, and is only a minor contributor to the total power loss [16, 24]. Hence we can assume that the power loss (attenuation) occurring in this Aluminum cable is mainly due to ohmic loss.

$$
\begin{gathered}
\delta=\frac{1}{\sqrt{\pi f \mu_{0} \sigma}} \\
R_{\text {loss }}=\sqrt{\frac{\pi f \mu_{0}}{\sigma}} \frac{l}{2 \pi(a-\delta / 2)}
\end{gathered}
$$

Equation (1) shows the loss resistance due to conductor loss. In (1) $\delta$ is the skin depth, ' $a$ ' is the cable radius, $\sigma$ is the conductivity, ' $l$ ' is the length of the cable under test, ' $\mathrm{f}$ ' is frequency in $\mathrm{Hz}$ and $\mu_{\mathrm{o}}$ is the permeability of free space. $R_{\text {loss }}$ is plotted in Fig. 5 as a function of frequency. The loss resistance at $2.5 \mathrm{GHz}$ only reaches approximately $0.15 \Omega / \mathrm{m}$.

Therefore we can conclude that the power dissipation due to ohmic loss is very low. Hence the attenuation values obtained from the simulations can be justified.

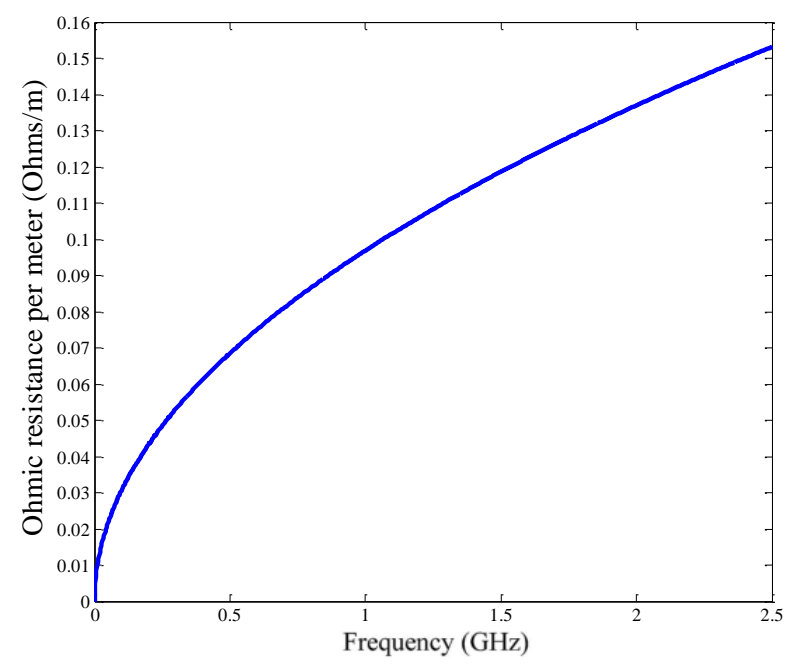

Fig. 5. Loss resistance vs frequency for Aluminum cables

\section{RF RADIATION FROM A SingLE OVERHEAD POWER LINE DUE TO PARTIAL DISCHARGE}

The wave propagation along a power line has been discussed previously [19, 25], along with UHF and VHF radiation from insulators [5 - 8]. However there has been minimal discussion on the electromagnetic radiation pattern created when a PD signal travels along a cable. It has been demonstrated that there is a significant level of radiated energy due to PD, which can be detected in the VHF and UHF regions. Earlier simulation works show that the radiation from an insulator generating PD displays an omni-directional radiation pattern [26, 27], and that the radiation energy from the PD activity is enough to excite the power cable.

A power cable excited by a PD pulse exhibits distinctive traveling wave radiation patterns at different frequencies. The plots in Fig. 6 display these patterns at various frequencies for the simulation setup given in Fig. 2. The radiation patterns in Fig. 6(b)-(f) display a travelling wave shape [23] since the cable's electrical length of $5 \mathrm{~m}$ is equal or longer than one wavelength at that particular frequency. Fig. 6(a) does not show the travelling wave radiation pattern since the cable's electrical length is 0.33 wavelengths at $20 \mathrm{MHz}$. This is an artefact of the limited simulation size, as a travelling wave radiation pattern would result if the simulated cable length was extended to $15 \mathrm{~m}$ (or greater), which is a full wavelength at 20 MHz.

A long wire antenna is a straight wire or cable with the length of one or more wavelengths [23]. It is an elementary antenna which has been used in short wave transmissions for a very long time. Long wire antennas exhibit a travelling wave radiation pattern. Hence, uninsulated Single Wire Earth Return (SWER) distribution cables can be classified as long wire antennas when the cable length is in excess of a wavelength at a particular frequency. 


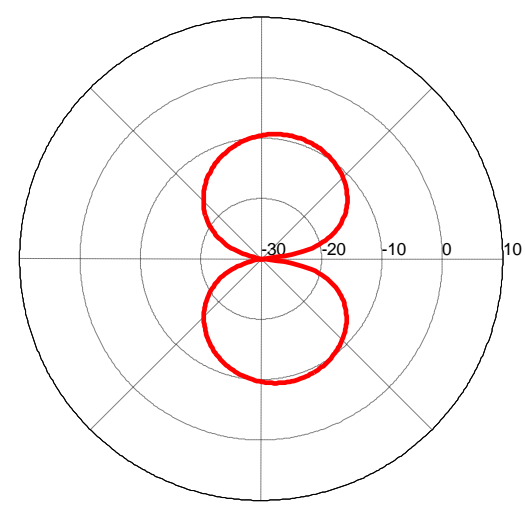

(a)

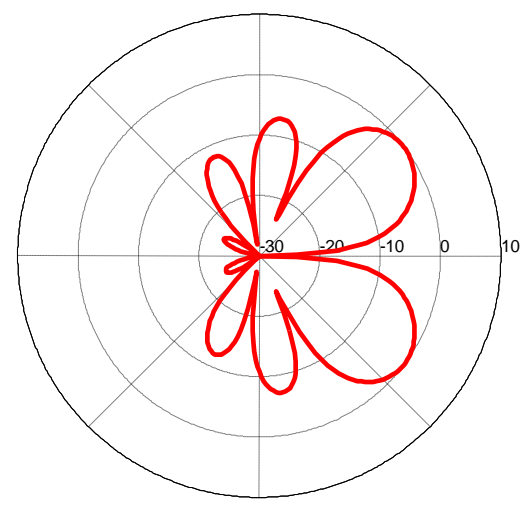

(c)

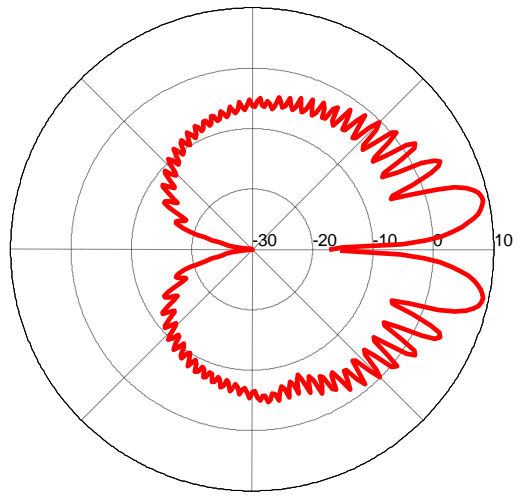

(e)

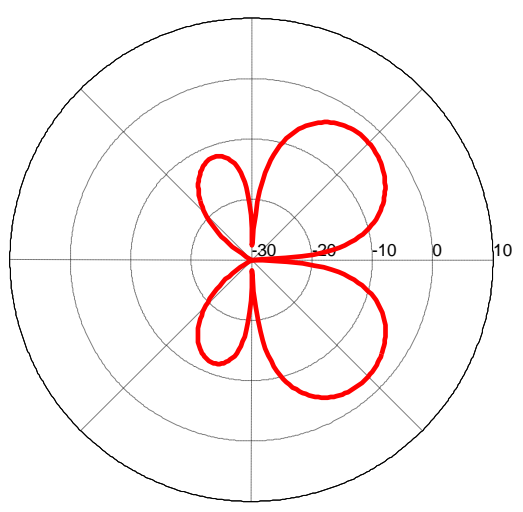

(b)

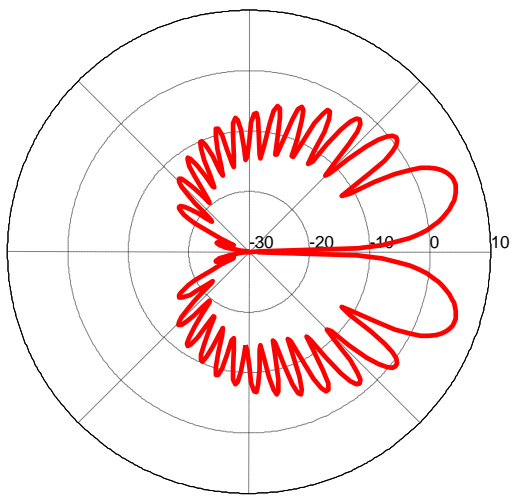

(d)

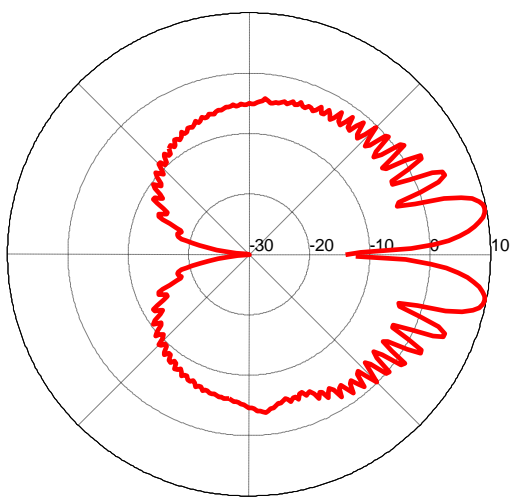

(f)

Fig. 6. Radiation patterns in the $\mathrm{x}-\mathrm{z}$ plane from a single un-insulated power cable at various frequencies (a) $20 \mathrm{MHz}$ (0.33 wavelengths) (b) $60 \mathrm{MHz}$ (1 wavelength) c) $100 \mathrm{MHz}$ ( 1.67 Wavelengths) (d) $400 \mathrm{MHz}$ (6.67 Wavelengths) (e) $900 \mathrm{GHz}$ (13.33 Wavelengths) (f) $1.1 \mathrm{GHz}$ (18.33 Wavelengths)

Directivity is a measure of how well an antenna emits or receives radiation in a particular spatial direction. The directivity of the un-insulated power cable in the direction of the main radiation lobe rises as frequency increases, as shown in Table I. Therefore higher frequency components of the propagating PD signal will show more significant radiation in a particular direction than lower frequency components. The angle between the cable direction and the maximum of the radiation pattern main lobe has reduces with incrementing frequency component. Hence, a judiciously placed RF can be used to efficiently detect radiated high frequency components universal to PD.

\section{ELECTROMAGNETIC RADIATION FROM A TYPICAL ELECTRICAL DISCHARGE}

Partial discharge can have various incarnations such as cavity discharge, surface discharge and dry-band arcing. Previous research has shown that cavity discharge is capable of generating high frequency components, particularly in 800 $\mathrm{MHz}-1100 \mathrm{MHz}$ region [2, 4]. However due to the quality control procedures used in insulator manufacture, the possibility of cavity discharge is significantly low. Surface discharge and dry-band arcing have been observed as common causes of insulator failure. Both result from insulation pollution and/or the presence of moisture. Hence it is 
important to examine power cable behavior for real PD signal collected experimentally.

TABLE I

Directivity AND MaIn Lobe DiReCTION AT VARIOUS FREQUENCIES

\begin{tabular}{|c|c|c|c|}
\hline \multicolumn{2}{|c|}{ Frequency } & \multirow{2}{*}{$\begin{array}{c}\text { Direction } \\
\text { of the } \\
\text { main lobe } \\
\text { From } \\
\text { Cable } \\
\text { Dength of the } \\
\text { 5m long cable }\end{array}$} & $\begin{array}{c}\text { Directivity } \\
\text { (dBi) }\end{array}$ \\
\hline 20 & $0.33 \lambda$ & -9.9 & 72 \\
\hline 60 & $1 \lambda$ & -2.6 & 47 \\
\hline 100 & $1.67 \lambda$ & 0 & 37 \\
\hline 400 & $6.67 \lambda$ & 6.1 & 19 \\
\hline 900 & $15 \lambda$ & 9.1 & 12 \\
\hline 1100 & $18.33 \lambda$ & 9.9 & 11 \\
\hline
\end{tabular}

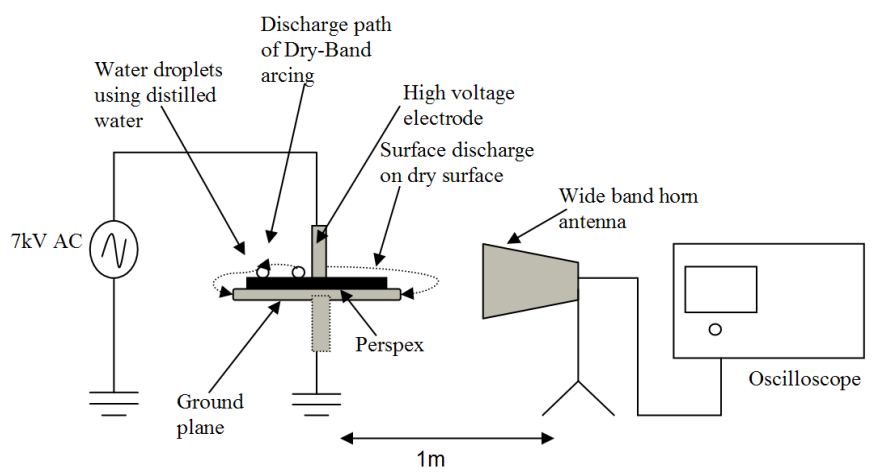

Fig. 7. Experimental setup to measure the radiated electromagnetic signal from PD

Fig. 7 presents the setup used to experimentally determine the common form of radiated signal from surface discharges and dry-band arcing. An $11.1 \mathrm{~cm} \mathrm{x} 14 \mathrm{~cm}$ x $1.6 \mathrm{~cm}$ dry Perspex sample was employed to investigate the surface discharge caused by $7 \mathrm{kV} 50 \mathrm{~Hz}$ power supply. A wideband horn antenna located $1 \mathrm{~m}$ away was used to measure the electromagnetic radiation from the discharge. Distilled water was then sprayed on to the sample to induce dry band arcing using the same HV power supply. Time domain data was collected each minute by a Tektronix TDS5104 oscilloscope with a sampling rate of $5 \mathrm{GS} / \mathrm{s}$. This was then converted via a Discrete Fourier Transformation (DFT) to the frequency domain over the range of 0 to $2.5 \mathrm{GHz}$.

Selected time and frequency domain responses of the two different discharges are shown in Fig. 8 and Fig. 9. Both surface discharge and dry-band arcing show a high level of activity in $20-100 \mathrm{MHz}$ frequency band. Elevated spectrum levels are also evident in the bands from $400-600 \mathrm{MHz}$ and $900-1000 \mathrm{MHz}$. Therefore, as detectable levels of radiation in these frequency bands are common to both types of PD activity they are of considerable interest for RF sensing. Referring to Table I, antenna directivity in these bands is high for a signal traveling along a un-insulated power cable, hence assisting detection.
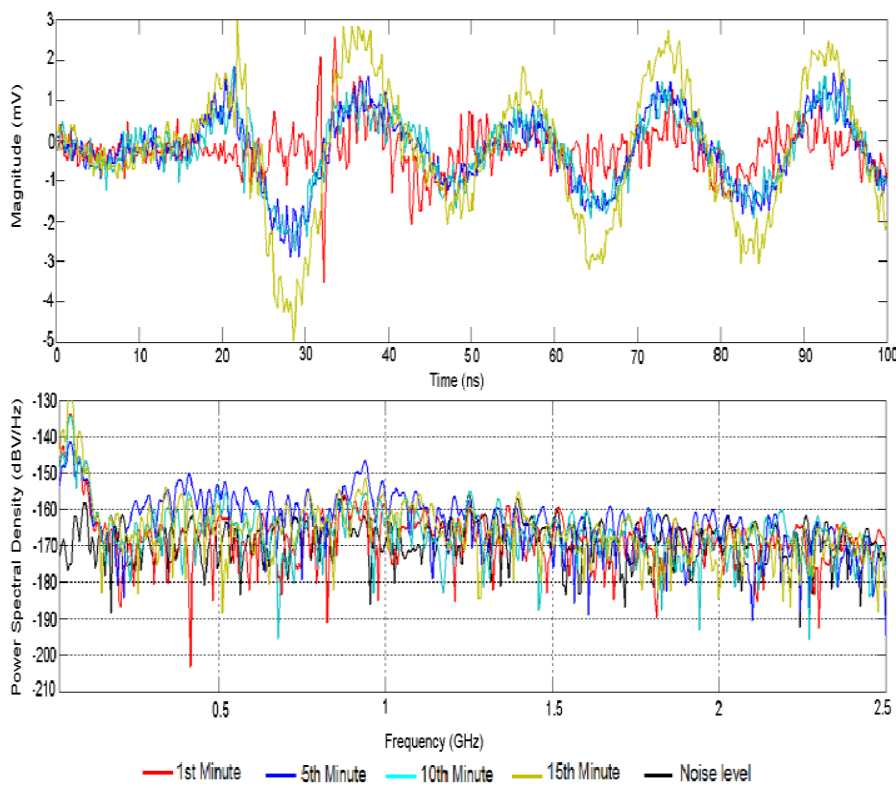

Fig. 8. Time and frequency domain representation of surface discharge
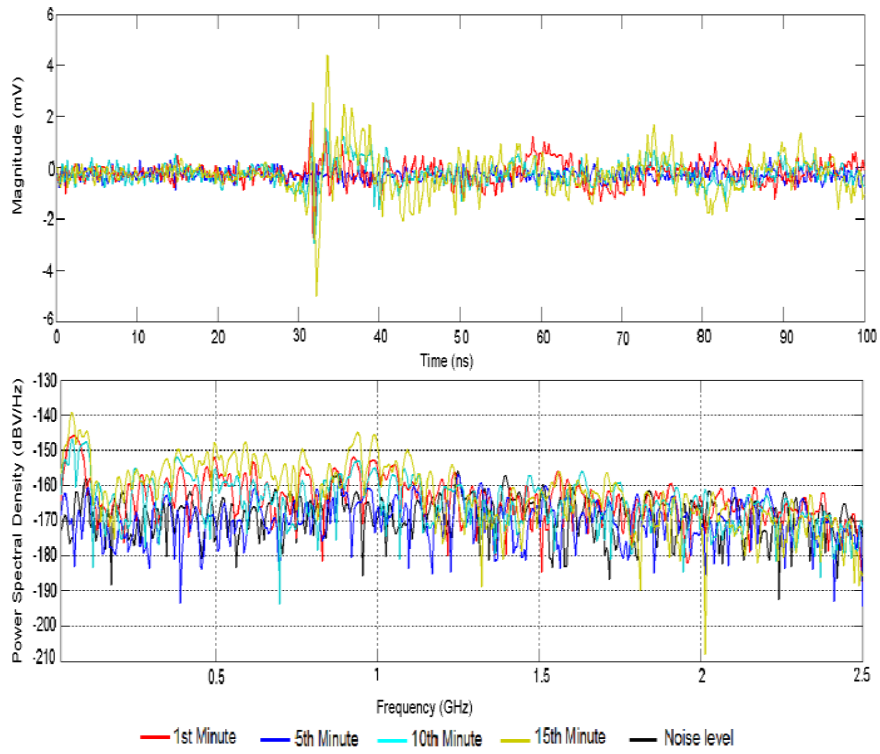

Fig. 9. Time and frequency domain representation of dry-band arcing

Common communication and broadcast bands such as keyless remote controls (433.05 MHz - 434.79 MHz), UHF television transmission $(520 \mathrm{MHz}-820 \mathrm{MHz})$ and cellular mobile telephones $(820 \mathrm{MHz}-915 \mathrm{MHz})$ may create disturbances for PD detection systems in the identified bands. 
However, these potential interferers are narrow band services, hence the detection frequency of an RF PD sensor can be designed to avoid these bands. For the practical implementation of a PD detection system for distribution lines, an extensive study of the signal to noise ratio and advanced noise filtering techniques is essential.

\section{RAdiATION FROM AN 11 KV ThreE Phase CABLE System}

Section IV primarily discussed the radiation activity of a single un-insulated power cable due to PD pulse propagation. Distribution networks are predominantly three phase systems, hence the investigation of signal propagation and coupling in a three cable architecture is important. Power distribution system cables are spaced apart from each other in order to minimize the interference from the electric fields of a propagating $50 \mathrm{~Hz}$ AC signal. The coupling between adjacent cables at higher frequencies resulting from propagating discharges is examined using the simulation setup shown in Fig. 10. Three $5 \mathrm{~m}$ long Aluminum cables are separated by a distance of $60 \mathrm{~cm}$, which is a standard spacing for $11 \mathrm{kV}$ overhead power distribution. The central cable has been excited by a Gaussian pulse, emulating a fault on the middle insulator. Voltage monitors connected to each cable are used to measure the signal in each cable.

The voltage signals detected at the end of each of the three cables are given in Fig. 11. The induced pulse measured on the left and right side are around 20 times smaller than the pulse measured from the middle cable, which had the directly connected input pulse. The pulse shape has changed considerably, indicating that the coupling is frequency dependant. For a PD detection system employing RF sensors, the affect these adjacent cables have on the radiation pattern of a propagating pulse is of primary concern.

The radiation patterns displayed in Fig. 12 compare the single and three cable systems at $400 \mathrm{MHz}$ and $900 \mathrm{MHz}$ in all three primary planes. As discussed in Section V, 400MHz and $900 \mathrm{MHz}$ are in the detectable radiation bands for surface discharges and dry-band arcing. The radiation patterns for the three phase cable system still displays the basic traveling wave shape. Distortion of the three cable pattern is seen in the $y-z$ plane due to the presence of the adjacent cables. A slight variation in the directivity on the main radiation lobe is also evident.

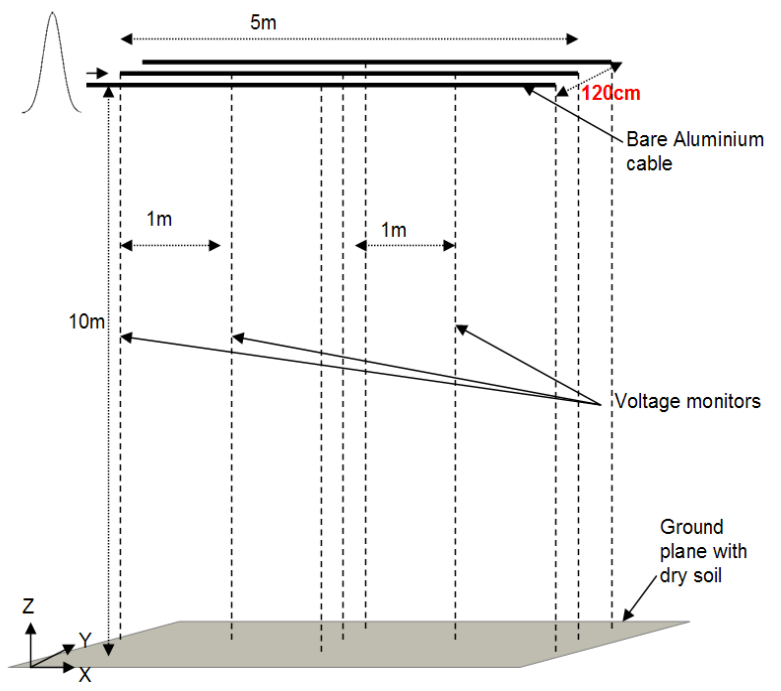

Fig. 10. Simulation configuration of a three cable system with the middle cable excited.

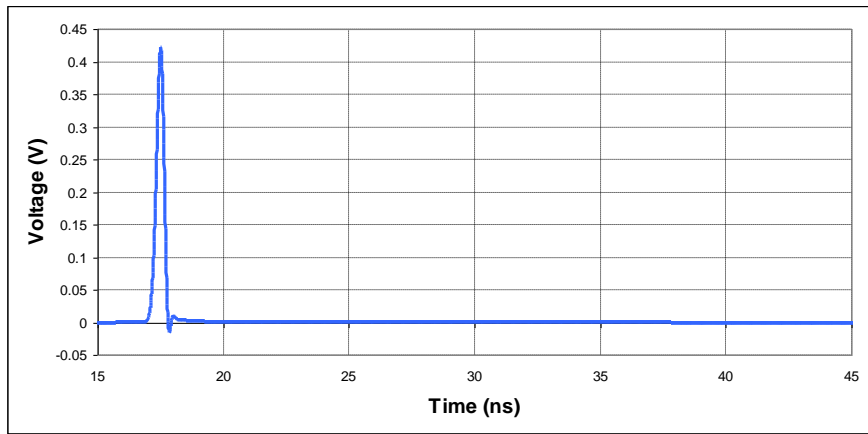

(a) Pulse measured at the end of the middle cable (Cable with PD source)

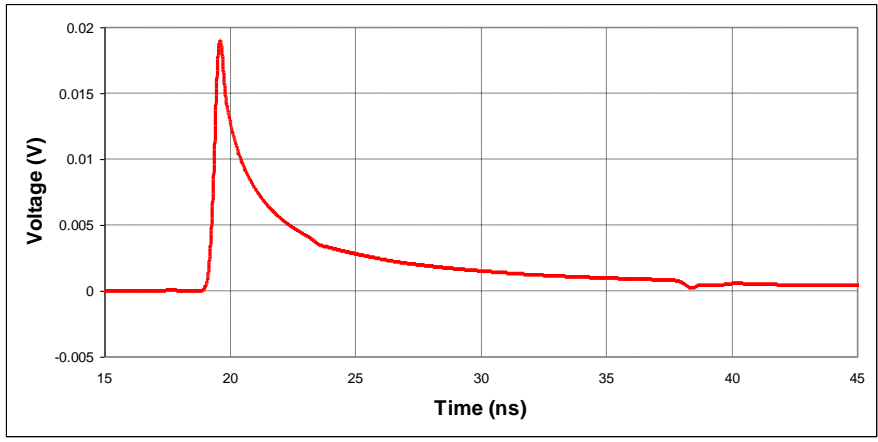

(b) Pulse measured at the end of the left cable

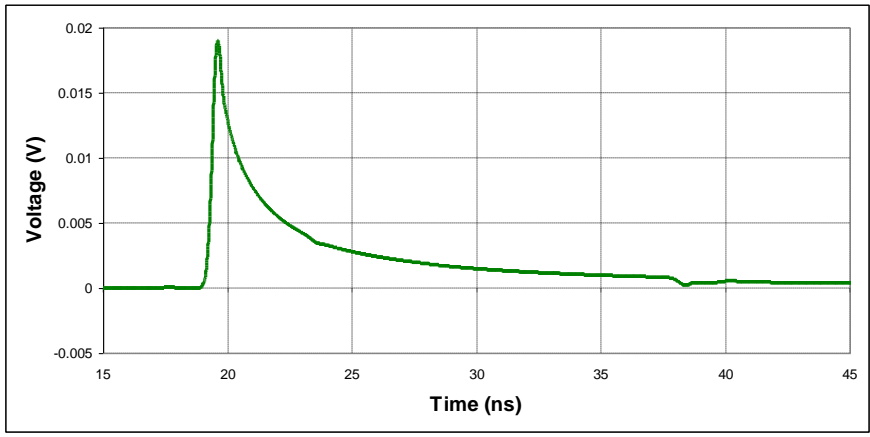

(c) Pulse measured at the end of the right cable

Fig. 11. Pulse measured at the end of each of the three cables 
A directivity comparison is provided in Table II. The directivity of the three cable system is about $1 \mathrm{~dB}$ higher than single cable system. This may be due to the induced pulse on the outer cables causing each cable act as an individual element of an array [23], resulting in increased directivity.

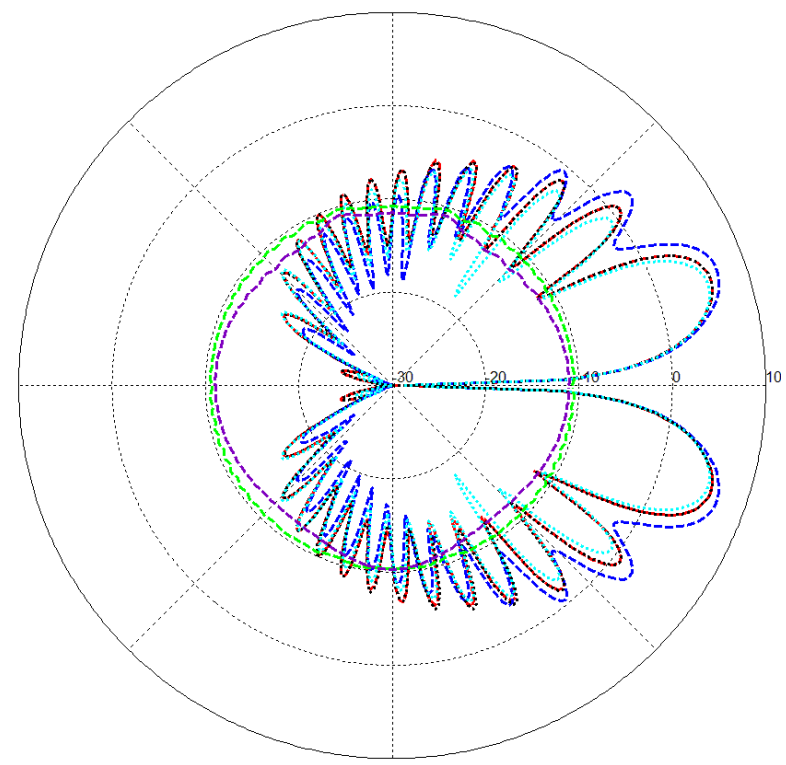

(a) Radiation pattern for $400 \mathrm{MHz}$

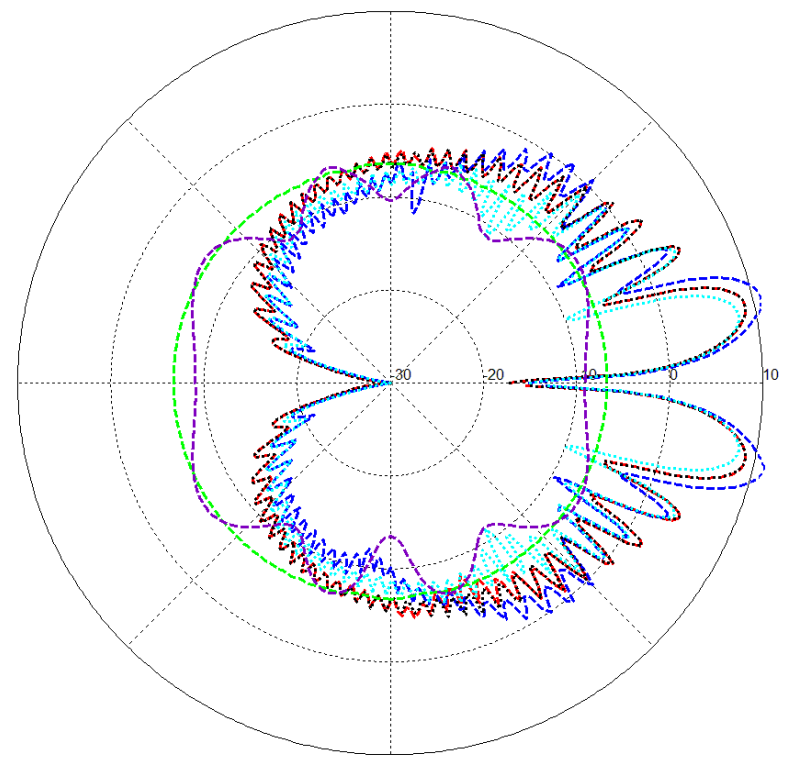

(b) Radiation pattern for $900 \mathrm{MHz}$

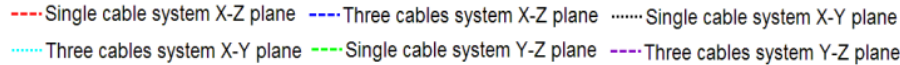

Fig. 12. Radiation patterns at $400 \mathrm{MHz}$ and $900 \mathrm{MHz}$ for single and three cable systems
TABLE II

DiRECTIVITY COMPARISON FOR SINGLE AND THREE CABLE CONFIGURATIONS

\begin{tabular}{|c|c|c|}
\hline \multirow{2}{*}{ Frequency (MHz) } & \multicolumn{2}{|c|}{ Directivity (dBi) } \\
\cline { 2 - 3 } & $\begin{array}{c}\text { Single } \\
\text { cable } \\
\text { system }\end{array}$ & $\begin{array}{c}\text { Three } \\
\text { cable } \\
\text { system }\end{array}$ \\
\hline 400 & 6 & 7 \\
\hline 900 & 9.1 & 10.37 \\
\hline
\end{tabular}

\section{CONCLUSIONS}

A discussion of the propagation and radiation behavior of PD on un-insulated overhead distribution lines has been presented in this paper. The bare Aluminum overhead cable shows very low attenuation levels, even at $\mathrm{GHz}$ frequencies. Hence high frequency components of a PD signal will travel for a significant distance along a cable, allowing for remote detection.

An analysis of the dominant frequency components of both surface discharge and dry-band arcing was experimentally deduced. It was shown that the frequency bands from $400-$ $600 \mathrm{MHz}$ and $900-1000 \mathrm{MHz}$ show a detectable level of radiation for both types of discharge.

The radiation patterns for the high frequency components of PD propagating on single wire and three phase systems have also been investigated. Traveling wave radiation patterns analogous to a long wire antenna are observed. High directivity values are recorded at 400 and $900 \mathrm{MHz}$, which are in the high radiation bands for surface discharge and dry-band arcing. Knowledge of the changing directivity and direction of main lobe radiation with frequency can be used to efficiently configure the orientation of an RF sensor in a PD detection an localization system.

\section{ACKNOWLEDGMENT}

This research was supported under Australian Research Council's Discovery Projects funding scheme (project number DP0880770).

\section{REFERENCES}

[1] S.A. Boggs, "Partial discharge part III: Cavity induced PD in solid dielectrics," IEEE Electrical Insulation Magazine, 1990. vol. 6, issue: 6, pp. 11-20.

[2] S.C. Fernando, W.S.T. Rowe, A. Bojovschi, and K.L. Wong, "Detection of $\mathrm{GHz}$ frequency components of partial discharge in various media," presented at 16th International Symposium on High Voltage Engineering (ISH 2009), Cape Town, South Africa, 2009.

[3] R. Sarathi and R. Umamaheswari, "Understanding the partial discharge activity of conducting particles in GIS under DC voltage using the UHF technique," European Transaction on Electrical Power, vol. 20, issue: 5, PP. 591-599, July 2009.

[4] B. Stewart, A.J. Reid, M.D. Judd and R.A. Fouracre, "UHF and IEC60270 correlation analysis of radiated frequency band measurements on resin insulation void samples," in Proc. 2007 Electrical Insulation Conference and Electrical Manufacturing Expo, Tennessee, USA, pp. 138-141. 
[5] M.D. Judd, L. Yang, and I.B.B. Hunter, "Partial discharge monitoring for power transformers using UHF sensors part 1: Sensors and signal interpretation," IEEE Electrical Insulation Magazine, vol. 21, issue: 2, pp. 5-14, March- April 2005.

[6] C. Min, K. Urano, L. You-Cheng, and A. Jinno, "Application of combined PD sensor for GIS PD detection and condition monitoring," presented at International Conference on Condition Monitoring and Diagnosis, Beijing, China, 2008.

[7] M.D. Judd, L. Yang, and I.B.B. Hunter, "Partial discharge monitoring for power transformer using UHF sensors. part 2: Field experience," IEEE Electrical Insulation Magazine, vol. 21, issue: 3, pp. 5-14, MayJune 2005

[8] K.L. Wong, "Application of very-high-Frequency (VHF) Method to Ceramic Insulators," IEEE Transactions on Dielectrics and Electrical Insulation, vol. 11, issue: 6 pp. 1057-1064, Dec. 2004.

[9] P.C.J.M. van der Wielen, "On-line detection and location of partial discharges in medium voltage power cables," Ph.D. dissertation, Technical University Eindhoven, 2005.

[10] U. Schichler, "A sensitive method for on-site partial discharge detection on XLPE cable joints," in Proc. $19975^{\text {th }}$ International Conference on Properties and Applications of Dielectric Materials, vol. 2, pp. 1099 1102.

[11] J. Zhu, L. Yang, J. Jia and Q. Zhang, "The design of Rogowski coil with wide band using for partial discharge measurement," in Proc. 2005 International Symposium on Electrical Insulating Materials (ISEIM 2005), Kitakyushu, Japan, vol. 2, pp. 518-521.

[12] G.M. Hashmi, "Partial discharge detection for condition monitoring of covered conductor overhead distribution networks using Rogowski coil," Ph.D. dissertation, Faculty of Electronics, Communications and Automation, Department of Electrical Engineering, Helsinki University of Technology, 2008.

[13] S. Boggs, A. Pathak, and P. Walker, "Partial discharge. XXII. High frequency attenuation in shieldedsolid dielectric power cable and implications thereof for PD location," IEEE Electrical Insulation Magazine, vol. 12, issue: 1, pp. 9-16, Jan-Feb. 1996.

[14] G. Mugala, "High frequency characteristics of medium voltage XLPE power cables," Ph.D. dissertation, School of Electrical Engineering, KTH Electrical Engineering, 2005.

[15] Specification for design and construction of high voltage overhead mains. EnergyAustralia, pp. 18-25, 2008.

[16] G.D. Reid and C.J. Kikkert, "Radiation from a single wire earth return power line," presented at EEEvolution Symposium, Cairns, 28-30 July 2008.

[17] M. Vakilian, T.R. Blackburn, and B.T. Phung "Evaluation of over voltage surges, and PD propagation on XLPE cables," in Proc. 2004 Australian Universities Power Engineering Conference (AUPEC 2004), Brisbane, Australia, pp. 178-183.

[18] G.M. Hashmi and M. Lehtonen, "Covered conductor overhead distribution line modeling and experimental verification for determining its line characteristics," presented at IEEE PowerAfrica 2007 Conference, South Africa, 2007.

[19] R.G. Olsen, "Power transmission electromagnetics," IEEE Antennas and propagation magazine, vol. 36, issue: 6, pp. 7-16, Dec. 1994.

[20] CST Microwave Studio [Online]. Available: http://www.cst.com.

[21] B. Krietenstein, R. Schuhmann, P. Thoma and T. Weiland, "The perfect boundary approximation technique facing the big challenge of high precision field computation," presented at The XIX International Linear Accelerator Conference (LINAC 98), Chicago, USA, 1998.

[22] L. Zhou, W. Li and S. Su, "The deduction of partial discharge pulse current from its radiating UHF signal," presented at The 7th International Power Engineering Conference (IPEC 2005), Singapore, 2005.

[23] C.A. Balanis, Antenna theory, 2nd ed., John Wiley \& Sons, 2004.

[24] C.J. Kikkert and G.D. Reid, "Radiation and attenuation of single wire earth return power lines at LF frequencies," in Proc. 2009 IEEE International Symposium on Power Line Communications and Its Applications (ISPLC 2009.), Dresden, Germany, pp. 68 -72 .

[25] R.G. Olsen, J.L.Young and D.C.Chang, "Electromagnetic wave propagation on a thin wire above earth," IEEE Transactions on Antennas and Propagation, vol. 48, issue: 9, pp. 1413-1419 ,Sep. 2000.

[26] A. Bojovschi, W.S.T. Rowe and K.L. Wong, "Electromagnetic field intensity generated by partial discharge in high voltage insulating material,". Progress In Electromagnetics Research, vol. 104, pp. 167$182,2010$.

[27] A. Bojovschi, W.S.T. Rowe and K.L. Wong, "Electromagnetic field intensity on cross-arm structures caused by electrical arcing," presented at Asia-Pacific Microwave Conference (APMC 2010), Yokohama, Japan, Dec. 2010.

\section{BIOGRAPHIES}

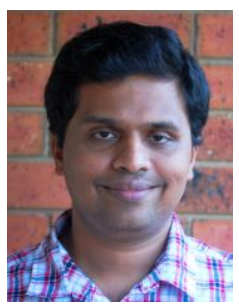

Sahan Chathura Fernando (S'10) was born in Kandy, Sri Lanka, in 1983. He received the B.Eng $\left(1^{\text {st }}\right.$ class Honors) degree in Electronic Engineering from RMIT University, Melbourne, Australia, in 2007, where he is currently working towards the Ph.D degree. His research interests include, EMI due to Partial discharge, Partial discharge sensing and Partial discharge detection and localization for overhead power lines. Mr. Fernando is a member of the IEEE MTT and DEIS societies.

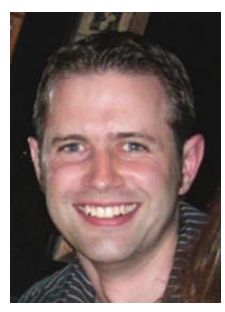

Wayne S. T. Rowe (M'04) received the Bachelor of Communication Engineering degree (Honors) and Ph.D. degree from RMIT University, Melbourne, Australia, in 1998 and 2002, respectively.

Dr. Rowe is currently a Senior Lecturer at RMIT University. He has performed research and consulting work for numerous industry partners, including Cochlear (Australia), DSTO Australia, Composite Materials Engineering Pty Ltd., SP Ausnet, and BAE Systems. His research interests include conformal, embedded and load bearing printed antennas and sensing structures, integrated antenna/microwave/photonic modules, tunable metamaterials, wireless power transmission, and RF sensors for high voltage power distribution lines. Dr. Rowe has also received an Australia Council Research grant on partial discharge detection using power line sensing technology.

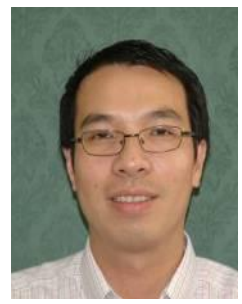

Khoi Loon Wong received the B.Eng (1st class) and $\mathrm{Ph} . \mathrm{D}$ degrees in 1997 and 2001 respectively. He is currently an Associate Professor in the School of Electrical and Computer Engineering at RMIT University. His research interests include the development of novel detection method for condition monitoring in power distribution and transmission system, investigation of pole top fire phenomena and mitigation method, long term performance of polymeric insulators and finite element analysis on electrical insulation system. He carried out many consultation works for power transmission and distribution companies in Australia. 